The validity of laboratory-based treatment research:

Bridging the gap between fear extinction and exposure treatment Sara Scheveneels ${ }^{1 *}$, Yannick Boddez $^{1}$, Bram Vervliet ${ }^{1,2}$, and Dirk Hermans ${ }^{1}$

${ }^{1}$ Centre for Learning Psychology and Experimental Psychopathology, University of Leuven, Leuven, Belgium. Email: Sara.Scheveneels@ppw.kuleuven.be, Yannick.Boddez@ppw.kuleuven.be, Dirk.Hermans@ppw.kuleuven.be

${ }^{2}$ Department of Psychiatry, Massachusetts General Hospital and Harvard Medical School, Boston, MA, USA. Email: Bram.Vervliet@ppw.kuleuven.be

This work was supported by KU Leuven Program Funding Grant PF/10/005 awarded to Dirk Hermans, by the Belgian Science Policy Office Grant P7/33 and by a Marie Curie International Outgoing Fellowship within the 7th European Community Framework Programme (PIOF-GA-2013-627743) awarded to Bram Vervliet.

\footnotetext{
* Corresponding author:
}

Sara Scheveneels

Centre for Learning Psychology and Experimental Psychopathology, University of Leuven Tiensestraat 102 - bus 3712 3000 Leuven, Belgium E-mail: Sara.Scheveneels@ppw.kuleuven.be 


\begin{abstract}
A major objective of experimental psychopathology research is to improve clinical practice via the experimental study of treatment mechanisms. The success of this endeavor depends on the external validity of the procedures used to model the treatment component in the laboratory. We propose a general framework and a set of specific criteria that will allow evaluating whether a certain laboratory procedure is a valid model for a certain clinical treatment. We illustrate this framework by evaluating the validity of extinction as a laboratory model for clinical exposure therapy. Although we acknowledge the merits of the extinction model, we argue that its validity might not be as firmly established as the research community assumes. We also use extinction as an example to demonstrate how considerations of the proposed criteria can stimulate further improvements to existing models of treatment. We conclude that the systematic assessment of external validity of treatment models is an important step towards bridging the gap between science and practice in the field of experimental psychopathology.
\end{abstract}

Keywords: Fear extinction; Exposure therapy; Return of fear; Validity; Experimental psychopathology; Translational research 


\section{The validity of laboratory-based treatment research: Bridging the gap between fear extinction and exposure treatment}

Experimental psychopathologists study the causal factors of pathological behavior under highly controlled conditions. According to Kimmel (1971), experimental psychopathology (EP) can be approached as both "the experimental study of pathological behavior" and "the study of experimental pathological behavior" (p. 7, see also Forsyth \& Zvolensky, 2002; Zvolensky, Forsyth, \& Johnson, 2013). The former approach concerns the experimental study of (factors that influence) pre-existing pathological behavior in clinical or subclinical subjects. In the latter approach of EP, 'pathological behavior' is experimentally induced in healthy (animal or human) subjects. A prerequisite for research in healthy subjects is a laboratory model of the pathological behavior: a set of behavioral, pharmacological, genetic or surgical manipulations that result in behavior that is similar to the pathological behavior. Pavlov (1927), to give an early behavioral example, produced behavior similar to neurosis by presenting his dogs with ambiguous stimuli. In a first phase of a relatively easy discrimination task, a circle but not an ellipse was presented together with food. Subsequent presentation with a stimulus somewhere in between a circle and an ellipse resulted in symptoms characteristic of neurosis. An example of a genetic manipulation is the cannabinoid receptor gene knockout mouse that exhibits behavioral changes that are similar to symptoms of schizophrenia (Fritzsche, 2001). Once the prerequisite of having a laboratory model of the pathological behavior is met, a plethora of research questions can be investigated (e.g., about individual differences or about the environmental factors that exacerbate such behavior; Vervliet \& Raes, 2013), and hence a better understanding of this behavior can be attained.

However, the ultimate aim of experimental psychopathologists is not to merely understand, but also to reduce pathological behavior. Despite a great amount of EP research, there are still opportunities for the further enhancement of clinical treatments. Only about half 
of the patients experience a full remission or respond to psychological treatment in a clinically meaningful way (Holmes, Craske, \& Graybiel, 2014). Moreover, an important subgroup of patients fails to maintain the effects of treatment in the long term and experiences relapse (e.g., Lipsitz, Mannuzza, Klein, Ross, \& Fyer, 1999; Steinert, Hofmann, Kruse, \& Leichsenring, 2014).

A straightforward factor that might add to the continued development of clinical treatment is more interaction between scientists and clinicians (e.g., Barlow, 1981; Berke, Rozell, Hogan, Norcross, \& Karpiak, 2011). In line with this, evidence-based strategies to disseminate and implement evidence-based interventions have recently started to develop (McHugh \& Barlow, 2010). In addition to enhancing communication, investing in the external validity of treatment models provides an opportunity to further improve clinical treatment. In laboratory research, complex psychological treatments are reduced to the putative core mechanisms (e.g., van den Hout, 1999). Such reduction contributes to the internal validity of the model: by providing control over confounding variables, reliable causal inferences can be made (van den Hout, Engelhard, \& McNally, in press). This is indeed considered one of the major strengths of EP research. Also, from a pragmatic point of view, it is more cost-effective and less time consuming to first test hypotheses in healthy volunteers using a basic treatment model before testing them in clinical trials. The question is, however, whether findings obtained with these simplified treatment models are still informative for clinical practice. In the present paper, we propose a general framework to answer this question. In particular, we discuss three criteria that have long been outlined in pharmacological research and have recently been used to evaluate the external validity of experimental models for psychopathology: face validity, construct validity and predictive validity (e.g., Abramson \& Seligman, 1977; Boddez et al., 2013; Luyten, Vansteenwegen, Van Kuyck, Gabriels, \& Nuttin, 2011; Vervliet \& Raes, 2013). To the best of our knowledge, this is the first time that 
these validity criteria are applied to a psychological treatment model. We illustrate this framework by evaluating the validity of extinction as a treatment model for clinical exposure therapy.

Fear extinction is seen as one of the most successful treatment models in the history of EP (Vervliet, Craske, \& Hermans, 2013). Its laboratory procedure entails unreinforced presentations of the conditioned stimulus (CS; e.g., geometrical shape), resulting in a decrease in the fear responses that were previously established by pairing the CS with an aversive (unconditioned) stimulus (US; e.g., electrical shock). This procedure is used to model clinical exposure therapy (e.g., Craske, Hermans, \& Vansteenwegen, 2006). In exposure-based treatments, the anxious client is repeatedly and systematically confronted with the fearprovoking situation (e.g., McNally, 2007). Despite being an efficacious treatment for a range of anxiety disorders, relapse is not uncommon after exposure-based treatments (e.g., Simpson et al., 2004). Limited generalization of extinction is generally considered to be the preeminent laboratory model for relapse following exposure therapy (e.g., Bouton, 2002). But how can we know whether continued research into fear extinction will teach us more about exposure treatment and ways to improve it? This question is fundamental to the issue of external validity and speaks directly to the challenge of bridging the gap between science and treatment.

Below, we discuss each of the three validity criteria (face validity, construct validity and predictive validity) in separate sections. We start each section with a definition of the criterion as applied to treatment models. Subsequently, we evaluate the extinction model using this criterion. We end each section by using extinction as an example to demonstrate how the validity approach can guide future developments in laboratory-based treatment research.

\section{Face validity}




\subsection{Definition}

In the present context, face validity refers to the surface similarity between the treatment model and the treatment itself. Surface similarity (face validity) is generally seen as a good starting point for the development of experimental models, but it is deemed as not very informative for the external validity of a model (e.g., Vervliet \& Raes, 2013). That is because mere similarities in procedure or result, however compelling, do not imply that similar mechanisms are involved (i.e., construct validity) or that treatment enhancing strategies that prove to be successful in the laboratory will also be successful in clinical practice (i.e., predictive validity). Nevertheless, surface similarity with clinical treatment does remain important, because it can serve as a continuing source of inspiration for creating new laboratory models or updating existing ones.

\subsection{Extinction and return of fear}

We now turn to the assessment of the extinction model using this criterion. Many researchers do refer to surface similarity when justifying their choice for fear extinction as a model of exposure treatment, as evidenced by the introduction sections of many published studies on extinction (e.g., Culver, Vervliet, \& Craske, 2015; Kindt \& Soeter, 2013; Leer \& Engelhard, 2015). In both extinction training and exposure-based treatment, the repeated confrontation with a fear-evoking situation or stimulus results in a decrease in outcome variables that are indicative of fear and anxiety (e.g., US-expectancy, subjective units of distress ratings). The same holds for laboratory models of relapse. Return of fear is a welldocumented phenomenon after fear extinction in the laboratory (Vervliet et al., 2013). Two paradigms frequently used for this purpose are renewal and reinstatement (Vervliet, Baeyens, Van den Bergh, \& Hermans, 2013). In renewal, a context switch between the extinction phase and the test phase causes a return of fear responses similar to a clinical relapse after successful treatment when the feared object or situation is encountered outside the therapy context 
(Effting \& Kindt, 2007). Reinstatement refers to the return of fear after unsignaled USpresentations between extinction and test, and can be seen as the equivalent of relapse after unsignaled panic attacks or if the previously feared stimulus is encountered after a stressful event or in a distressing situation (Dirikx, Hermans, Vansteenwegen, Baeyens, \& Eelen, 2007; Haaker, Golkar, Hermans, \& Lonsdorf, 2014). In conclusion, at face value fear extinction seems to be a sufficiently good treatment model of exposure therapy.

\subsection{Future research}

Researchers can continue to invest in increasing the surface similarity between the extinction procedure and exposure treatment. For example, it has been argued that basic stimulus sets such as geometrical shapes lack the complexity of real-world experiences (e.g., Barry, Griffith, De Rossi, \& Hermans, 2014). Some researchers therefore turn to the use of 3D virtual reality technology that allows administering extinction training under conditions that are closer to real-life situations (e.g., Dunsmoor, Ahs, Zielinski, \& LaBar, 2014). Using more complex, multi-sensory stimuli (e.g., auditory, tactile, olfactory, visual) can be a conceivable step in increasing the procedural overlap between extinction and exposure therapy (for a similar argument, see Waters, LeBeau, \& Craske, in press). In addition, extensions of the extinction model aimed at improving its face validity can target similarities in outcome measures. Behavioral avoidance is an important source of impairment in daily functioning in pathological anxiety (Barlow, 2002) and is frequently used as an outcome measure in clinical exposure studies, by using a behavioral approach task (e.g., Niles, Craske, Lieberman, \& Hur, 2015). The external validity of extinction research might therefore benefit from including behavioral avoidance as an outcome measure in addition to expectancy or fear ratings and psychophysiological indices of fear (e.g., van Meurs, Wiggert, Wicker, \& Lissek, 2014; Vervliet \& Indekeu, 2015). 
However, as mentioned before, enhancing the surface similarity of the extinction model does not by itself imply enhanced external validity with regard to underlying mechanisms or enhanced predictive value. Future research should therefore verify whether extensions of the extinction model aimed at increasing face validity do add to the transfer of successful interventions investigated in the laboratory to clinical exposure therapy. The validity criteria that are typically considered more decisive — construct validity and predictive validity — are discussed in the next sections.

\section{Construct validity}

\subsection{Definition}

The criterion of construct validity is met if the psychological mechanisms that drive behavioral change in the treatment model are the same as those that drive behavioral change in clinical treatment. Making this comparison requires a profound theoretical understanding of the mechanisms at play in the treatment model and in clinical treatment. Without an elaborate theoretical ground, the model might resemble the clinical treatment in terms of surface similarity (i.e., face validity), but further developments to optimize the clinical treatment based on the model will be hampered. That will, for example, be the case if an intervention that shows promise in the laboratory model exerts its effect through targeting a cognitive process that is at play in the model, but not in the clinical treatment. In such case the promise of the intervention will not be fulfilled in clinical treatment. In addition, construct validity is essential for the generation of theory-based optimization strategies.

\subsection{Extinction and return of fear}

\subsubsection{Extinction}

The currently dominant theory attributes extinction effects to an inhibitory learning mechanism (e.g., Bouton, 2002). The central tenet of this theory is that, rather than a destruction of the original excitatory CS-US association, an additional inhibitory CS-noUS 
association is learned throughout extinction training. This inhibitory association cancels out the original excitatory association, resulting in low to no conditioned responding when both these associations are activated. The theory additionally assumes that retrieval of the inhibitory association is modulated by the context, which allows it to explain the limited generalization of extinction performance. The inhibitory learning approach has proven its merits in accounting for extinction phenomena at the behavioral level (e.g., Bouton, 1993) and did find support in neurobiological research as well. As a result of extinction training, it is observed that prefrontal areas show an increase in activity, whereas areas activated during fear acquisition (e.g., the amygdala) show a decrease in activity, often interpreted as the former areas inhibiting the latter (e.g., Milad et al., 2007; Milad et al., 2005; Milad \& Quirk, 2012; Phelps, Delgado, Nearing, \& LeDoux, 2004).

High construct validity of the extinction treatment model would imply that a similar inhibitory mechanism drives the effects of exposure therapy. Speaking to its success, the inhibitory learning approach has provided useful recommendations for conducting clinical exposure therapy (see Craske, Treanor, Conway, Zbozinek, \& Vervliet, 2014; Pittig, van den Berg, \& Vervliet, 2016). Rather than pursuing fear reduction during treatment, which is a central component in habituation-based theories of exposure therapy such as the Emotional Processing Theory (e.g., Foa \& Kozak, 1986), the inhibitory learning approach focuses on enhancing inhibitory learning and facilitating the retrieval of the inhibitory association following successful treatment (Craske et al., 2008; Craske, Liao, Brown, \& Vervliet, 2012). Theoretically speaking, acquisition of an inhibitory association can be strengthened by, for example, maximizing expectancy violation, deepened extinction (i.e., multiple CS's are presented together during extinction after being extinguished separately; Culver, et al., 2015), and occasional reinforcement during extinction (Craske et al., 2014). Retrieval of an inhibitory association can be facilitated, amongst others, by the use of retrieval cues (e.g., 
Vansteenwegen et al., 2006) and by inducing variability in timing, stimuli and contexts (e.g., Bandarian-Balooch, Neumann, \& Boschen, 2012). Although there is a need for further evidence, some of these strategies have proven successful in optimizing exposure therapy, hence providing support for a role of the inhibitory learning mechanism in exposure therapy (e.g., Mystkowski, Craske, Echiverri, \& Labus, 2006; Rowe \& Craske, 1998a; Tsao \& Craske, 2000; Vansteenwegen et al., 2007). Furthermore, neuroimaging research suggests that the neural mechanisms underlying exposure therapy are similar to those supporting inhibitory learning as a crucial mechanism underlying extinction. In particular, a normalization of amygdala responses is observed after exposure therapy (Goossens, Sunaert, Peeters, Griez, \& Schruers, 2007), which is modulated by increased prefrontal activity (e.g., Felmingham et al., 2007; Hauner, Mineka, Voss, \& Paller, 2012). Felminghan, Dobson-Stone, Schofield, Quirk, and Bryant (2012) found that BDNF genotype, associated with reduced inhibition of the amygdala by prefrontal areas, predicts poor exposure treatment response. These results are consistent with findings from extinction research (Soliman et al., 2010).

At the same time, exposure therapy most likely encompasses more than the acquisition of an inhibitory association (e.g., Carey, 2011; Hofmann, 2008; Lovibond, 2004). Among other things, real-life exposure treatment might also recruit from other processes studied in the associative learning tradition, including US-habituation, US-devaluation and counterconditioning (e.g., Jaycox, Foa, \& Morral, 1998; Tyron, 2005). Although exposure to the US is unethical in some cases, two notable exceptions are the treatment of social anxiety and panic disorder. In the treatment of social anxiety, the client can be exposed to social rejection (Craske et al., 2014). In the treatment of panic disorder, the feared physical sensations (e.g., hyperventilation, increased heart rate, dizziness) are deliberately induced during interoceptive exposure, and this occasionally results in a full-blown panic attack (Craske \& Barlow, 2014). By experiencing panic attacks during treatment and in the presence 
of the therapist, clients can come to evaluate a panic attack as less dangerous and aversive (i.e., US-revaluation; Rescorla, 1973). Reinforcing feedback and compliments by the therapist and surrounding others might also result in counterconditioning: the feared stimulus is presented together with a positive event (i.e., compliments) that might change the valence of the feared stimulus (De Houwer \& Hughes, in press).

In addition, whereas extinction is typically investigated in a Pavlovian procedure in which the participant is passively exposed to the CS, operant processes most likely play an important role in exposure-based treatments (Bouton \& Todd, 2014). During clinical exposure, clients not only learn to refrain from avoidance behaviors, but are also encouraged to actively approach the feared situation. This approach behavior might add to the effects of exposure in several ways. First, merely approaching an object leads to more positive attitudes towards that object (Jones, Vilensky, Vasey, \& Fazio, 2013). Second, clients learn to acquire control over their behavior despite being anxious and experience that they are able to cope with the feared situation, leading to an increased sense of self-efficacy (e.g., Tryon, 2005). This operant component is no part of the extinction treatment model, although it is considered to be one of the primary therapeutic targets by many therapists in clinical practice (Hayes, Strosahl, \& Wilson, 2003, but see van Uijen, van den Hout, and Engelhard, 2015).

It can be concluded that the construct validity of extinction as a model of exposure therapy is not unequivocally supported and needs to be elucidated more clearly. While acknowledging the considerable success of the inhibitory learning account, we also argued that there are mechanisms that are at work in exposure treatment but not in the extinction model, including US-habituation, counterconditioning and approach behavior (McConnell \& Miller, 2014).

\subsubsection{Return of fear}

We now extend our analysis from extinction as a model of exposure therapy to return of fear as a model of relapse. Based on laboratory research on return of fear, the research community 
aims to draw conclusions about relapse and its prevention in clinical practice. Accordingly, it is important that the return of fear observed after extinction training is mediated by similar mechanisms as relapse after exposure treatment. So, the question becomes: are similar mechanisms responsible for the return of extinguished fear responses and for clinical relapse? Processes at work in exposure therapy, but not in the extinction treatment model, might exert influences on the generalization of the behavioral change. The small amount of available evidence suggests that some of these processes —more specifically, US-habituation and counterconditioning - are better retained over time and are less vulnerable to generalization decrement than extinction training (Dibbets, Poort, \& Arntz, 2012; Haesen \& Vervliet, 2015; Kerkhof, Vansteenwegen, Baeyens, \& Hermans, 2010; but see Bouton, 2002; Brooks, Hale, Nelson, \& Bouton, 1995). Haesen and Vervliet (2015), for instance, found that participants who were exposed to the US (i.e., a procedure to obtain US-habituation) showed less renewal in skin-conductance response compared to participants who were exposed to the CS (i.e., standard extinction training). Isolating the inhibitory learning component of exposure therapy in laboratory research might therefore result in ignoring the interplay between such processes and in an incomplete understanding of how the effects of exposure therapy generalize.

Another potential confound in translating laboratory findings on return of fear to clinical practice is that, arguably, laboratory phenomena such as renewal and reinstatement are adequate models for temporarily re-experiencing fear in real life, but not necessarily for clinical relapse. In the laboratory, return of fear is typically defined as the increase in USexpectancy and physiological fear responses between the end of extinction training and the first trial of an unreinforced test phase (e.g., Barry, Griffith, Vervliet, \& Hermans, 2016). However, return of fear observed in the laboratory is typically not persistent: immediately after the first test trial, a steep decline in the 'returned' fear responses is observed (e.g., Barry et al., in press; Vervliet, Kindt, Vansteenwegen, \& Hermans, 2010). Therefore, phenomena 
such as renewal and reinstatement might correspond to a short-term recurrence of fear or a lapse rather than a full-blown relapse (i.e., a long-term recurrence of the full symptomatology). Although in clinical practice a lapse can be a precursor for a full relapse, not all clients who experience a provisional recurrence of fear after treatment actually relapse (Vervliet et al., 2013). A critical mediator in the transition between a lapse and an actual relapse could be re-engaging in excessive and rigid avoidance behaviors in response to a recurrence of fear. Similar to its role in the etiology and maintenance of anxiety disorders, it seems reasonable to assume that rigid avoidance in response to a short-term recurrence of fear after treatment takes away the opportunity to experience that the expected or feared outcomes do not occur and that one is able to cope with the fear-eliciting situation (Forsyth, Eifert, \& Barrios, 2006; Lommen, Engelhard, Sijbrandij, van den Hout, \& Hermans, 2013; Mineka \& Zinbarg, 2006). Notably, models for relapse typically used in the laboratory are restricted to a Pavlovian procedure and do not include an opportunity to perform avoidance behavior when experiencing return of fear at the first test trial. Because participants cannot escape from or avoid the CS in these procedures, they will experience that the US does not occur and immediate (re-)extinction will take place after the first test trial.

Admittedly, because of ethical considerations laboratory research will always be limited in its ability to model clinical relapse. However, below we illustrate how feasible adjustments to the extinction model could result in a laboratory model of relapse that might better reflect clinical relapse.

\subsection{Future research}

A number of suggestions to optimize the extinction model of exposure therapy can be derived from the evaluation of its construct validity. We discussed that additional processes, disregarded in current extinction research, might be at work in exposure therapy and that some of these processes are less subject to generalization decrement. An obvious research 
strategy would be to form hypotheses about the various mechanisms at work in exposure therapy and to investigate whether they show effects on extinction learning and its generalization. Let us illustrate this with the example of operant processes. As said, patients are encouraged to actively approach the feared situation during exposure, which might lead to more positive attitudes towards the feared object (Jones et al., 2013) and to an increased sense of self-efficacy (e.g., Tryon, 2005). In future research, one could add an approach component by having participants pull the CS towards them with a joystick during the extinction phase (with the CS enlarging in response to the joystick movement; Krypotos, Arnaudova, Effting, Kindt, \& Beckers, 2015) and assess whether that changes the course of extinction and its generalization. We also argued that return of fear observed in laboratory procedures is typically not persistent due to immediate (re-)extinction. Including the possibility to avoid the CS or escape from the CS when testing the generalization of extinction might better reflect what happens in clinical practice and could result in more persistent return of fear.

The decision to update a standard laboratory model should, however, depend on whether including such extra components adds to the successful transfer of laboratory findings to clinical exposure therapy (i.e., the predictive validity). For example, an extinction model that includes these operant components should only replace the standard extinction model if it allows drawing stronger conclusions of clinical significance. We further elaborate on this type of validity in the next section.

\section{Predictive validity}

\subsection{Definition}

Whereas construct validity concerns the question whether or not the same theoretical mechanisms are at work in the model and in the clinical treatment, predictive validity is a criterion that relates to the question whether performance in the model predicts performance in the clinical treatment. Thus claims about latent psychological mechanisms are at the heart 
of construct validity, whereas predictive validity in principle remains silent with respect to these mechanisms.

We distinguish two aspects in evaluating the predictive validity of psychological treatment models. A first aspect refers to testing whether individual differences in performance in the model predict the course and outcome of the clinical treatment. According to this aspect, a model has predictive validity if individuals who perform better in the model also benefit more from the clinical treatment. A second aspect of evaluating the predictive validity concerns testing whether interventions and factors that influence behavior in the model also influence the clinical treatment and vice versa. This aspect is directly attached to the translational value of the model.

\subsection{Extinction and return of fear}

Testing the first aspect of predictive validity requires investigating whether individual extinction performance is correlated with performance in exposure therapy. An important step would be to assess whether individuals who show steeper extinction curves in the laboratory also show greater decreases in indices of fear and anxiety during exposure treatment (i.e., correlation between the course of extinction and exposure). Similarly, individuals who show incomplete extinction would be expected to experience more residual anxiety at the end of treatment (i.e., correlation between the immediate outcome of extinction and exposure). Furthermore, the predictive validity of laboratory models for relapse can be tested by examining whether the amount of return of fear observed in the model is correlated with relapse after exposure therapy. Surprisingly, these tests have not been carried out in a systematic way.

The second aspect of predictive validity involves testing whether interventions of interest have similar effects on performance in the extinction model and exposure therapy. This aspect of predictive validity can be demonstrated in two directions: from the clinical treatment to the 
model and from the model to the clinical treatment. The former involves showing that factors that are known to influence clinical exposure treatment influence extinction training in a similar way. The latter involves the successful translation of interventions first tested in the extinction model to exposure therapy. Below, we discuss research on self-efficacy and Dcycloserine to illustrate both directions of this type of predictive validity.

Self-efficacy or the belief that one can effectively cope with fear-eliciting situations, is an important determining factor for both immediate and long-term effects of exposure therapy (e.g., Goldin et al., 2005). In particular, increases in self-efficacy have been found to mediate the effects of exposure-based treatment. Similar effects of self-efficacy on extinction would provide an argument for its predictive validity. A recent study indeed showed that adding verbal persuasion aimed at increasing self-efficacy in a human fear conditioning paradigm facilitated extinction of fear (Zlomuzica, Preusser, Schneider, \& Margraf, 2015).

The second example illustrates predictive validity in the other direction, from the extinction model to exposure therapy. Administering D-cycloserine (DCS), a partial agonist at the glycine-binding site of the N-methyl-D-aspartate receptor in the amygdala, has been shown to facilitate fear extinction and strengthen extinction memory in rodents (e.g., Vervliet, 2008; Walker \& Davis, 2002). If extinction is a valid model for exposure therapy, adding DCS should improve the outcome of clinical exposure therapy in a similar way. This was confirmed in several meta-analyses (Bontempo, Panza, \& Bloch, 2012; Norberg, Krystal, \& Tolin, 2008; Rodrigues et al., 2014; but see Hofmann et al., 2013; Ori et al., 2015).

\subsection{Future research}

There is plenty of room for future research inspired by the evaluation of the predictive validity of extinction as a model of exposure therapy. The most important challenge for future research remains to test whether individual differences in the course and outcome of 
extinction training can predict the course and outcome of clinical exposure treatment. These tests are a relatively straightforward way to assess the predictive validity of extinction.

With regard to the second aspect of predictive validity, a substantial subset of extinctionenhancing strategies have not been tested systematically in exposure therapy (e.g., Craske et al., 2014; Pittig, et al., 2016). Future translational research is warranted to test the effects of strategies such as deepened extinction (Culver et al., 2015) and occasional reinforcement (Culver, 2013) in clinical exposure studies. In the other direction, it can be examined whether variables and strategies that have proven successfully in optimizing exposure therapy, such as affect labeling (Kircanski, Lieberman, \& Craske, 2012; Niles et al., 2015) and expandingspaced exposure schedules (Rowe \& Craske, 1998b; Tsao \& Craske, 2000) can attenuate return of fear in human fear extinction as well.

The second aspect of predictive validity involves bridging the gap between laboratory techniques and clinical practice. It is, however, important to note that, with regard to our present purposes, the goal of these research studies would primarily be to assess the external validity of the extinction model. That is, we here argue for these translational studies because they are a means to evaluate whether extinction is a good model for exposure therapy, rather than because they involve translating a specific and promising laboratory technique to clinical practice.

\section{Conclusion and Discussion}

The issue of external validity has received ample interest in pharmacological research and some interest in EP research concerned with the modeling of psychopathology (e.g., Abramson \& Seligman, 1977; Vervliet \& Raes, 2014). The external validity of models of psychological treatment, although no less important, has received less attention. Threatened external validity of treatment models, amongst other factors, can explain why promising findings of experimental research do not generalize to clinical treatment. This has led some 
clinically-oriented researchers to argue in favor of testing interventions directly in clinical research and skip experimental approaches (Sloan, 2014). However, EP treatment research can make a unique contribution to the advancement of (transdiagnostic) treatment next to clinical studies by offering a profound understanding of treatment mechanisms. To maximize the translational value of EP research, it is, however, important that treatment models are subjected to systematic evaluation with regard to their external validity. In the present paper, we propose a framework for such evaluation. In particular, we demonstrate how the validity criteria previously outlined in pharmacological research (i.e., face validity, construct validity and predictive validity) can be applied to models of psychological treatment. Using extinction as a model for exposure-based therapy, we illustrate how this framework is not only suitable to evaluate treatment models, but can also stimulate future research to optimize models for psychological treatment.

Face validity, or the surface similarity between the treatment model and the clinical treatment, can be considered a good starting point and a source of inspiration for the further development of a model. However, it is not a sufficient ground for the external validity of a treatment model. We concluded that extinction has sufficient face validity and that even higher face validity could be achieved by including behavioral avoidance as an outcome measure and by making use of more complex, multi-sensory stimuli.

The construct validity of a treatment model depends on whether the mechanisms that drive behavioral change in the model correspond to those underlying the clinical treatment. An elaborate theoretical framework is indispensable for this endeavor. We acknowledged that Bouton's inhibitory learning theory (1993) does provide a data-supported, parsimonious, and simple foundation for understanding extinction and most recovery effects. However, there are reasons to believe that it is not sufficient to tell the whole story when applied to clinical exposure and relapse (McConnell \& Miller, 2014). Several additional mechanisms might 
account for the effects of exposure therapy, including US-habituation, US-devaluation, counterconditioning, and operant learning. Future research could benefit from taking these additional mechanisms into account. The research suggestions that we provided demonstrate that extinction research permits such extension.

The predictive validity of a laboratory model is directly related to its translational nature and therefore of great pragmatic value. A first aspect of the predictive validity is to test whether the course and outcome of the clinical treatment can be predicted by individual differences in performance in the model. An important target for future research in the field of extinction is to carry out these tests in a systematic way. A second aspect of the predictive validity is to investigate whether factors and interventions have a similar effect in the model and the clinical treatment. As said, a substantial subset of manipulations has not been systematically examined with regard to whether they have a similar impact on extinction and exposure therapy.

It is important to note that the three criteria of external validity are closely related. The procedure to which a clinical treatment is reduced in the laboratory is developed on the basis of theoretical assumptions about the core mechanisms at work in treatment. This concerns the construct validity of the treatment model. This reduction is an inherent part of the experimental method used in EP research and enables EP researchers to gain control over confounding variables, thereby contributing to internal validity. At the same time, strong reduction of a clinical treatment might detract from the face validity of a treatment model, whereas investing in face validity might indirectly add to construct and predictive validity. Although there is definitely not a one-to-one relation, it can be assumed that the greater the overlap at face value between the treatment model and the clinical treatment, the greater the chance that the model includes factors or processes that are crucial in the clinical treatment. However, this generally also results in a more complex laboratory model. The critical test for 
determining to what extent a clinical treatment can be simplified in the laboratory is the predictive validity of the model (van den Hout, et al., in press). If a highly simplified, basic treatment model has satisfactory predictive value, this basic model has to be preferred above a more complex model with equal predictive validity (cf. Ockham's razor). If, however, excessive reduction significantly dilutes the predictive validity of the treatment model, the more complex model is recommended.

Predictive validity cannot only be used to determine the optimal balance between face validity and construct validity, but is also more directly related to construct validity. In particular, it can be argued that a model that includes the underlying processes of the clinical treatment will also have a greater predictive value. This interaction can again be illustrated with inhibitory learning theory. If inhibitory learning is a crucial process underlying both extinction and exposure therapy, it is more likely that strategies and interventions for enhancing inhibitory learning and its retrieval exert a similar effect on extinction and exposure.

In conclusion, we were inspired by the observation that the progress of psychological treatment is lagging behind theoretical advances and promising findings in the laboratory. We hope that assessment of external validity through the proposed criteria can stimulate the further optimization of treatment models and help to bridge the gap between laboratory-based treatment research and clinical practice. 


\section{References}

Abramson, L., \& Seligman, M. (1977). Modeling psychopathology in the laboratory: history and rationale. In J. Maser \& M. Seligman (Eds.), Psychopathology: Experimental Models (pp. 1-26). San Francisco: W. H. Freeman and Co.

Bandarian-Balooch, S., Neumann, D., \& Boschen, M. J. (2012). Extinction treatment in multiple contexts attenuates $\mathrm{ABC}$ renewal in humans. Behaviour Research and Therapy, 50, 604-609. doi:10.1016/j.brat.2012.06.003

Barlow, D. H. (1981). On the relation of clinical research to clinical practice: Current issues, new directions. Journal of Consulting and Clinical Psychology, 49, 147-155.

Barlow, D. H. (2002). Anxiety and its disorders: The nature and treatment of anxiety and panic. New York, NY: Guilford Press.

Barry, T. J., Griffith, J. W., De Rossi, S., \& Hermans, D. (2014). Meet the Fribbles: Novel stimuli for behavioural research. Frontiers in Psychology, 5, 1-8. doi:10.3389/fpsyg.2014.00103

Barry, T, J., Griffith, J. W., Vervliet, B., Hermans, D. (2016). The role of stimulus specificity and attention in the generalization of extinction. Journal of Experimental Psychopathology, 7, 143-152. doi:10.5127/jep.048615

Berke, D. M., Rozell, C. A., Hogan, T. P., Norcross, J. C., \& Karpiak, C. P (2011). What clinical psychologists know about evidence-based practice: Familiarity with online resources and research methods. Journal of Clinical Psychology, 67, 329-339.

Boddez, Y., Baeyens, F., Luyten, L., Vansteenwegen, D., Hermans, D., \& Beckers, T. (2013). 
Rating data are underrated: Validity of US expectancy in human fear conditioning. Journal of Behavior Therapy and Experimental Psychiatry, 44, 201-206. doi:10.1016/j.jbtep.2012.08.003

Bontempo, A., Panza, K. E., \& Bloch, M. H. (2012). D-cycloserine augmentation of behavioral therapy for the treatment of anxiety disorders: A meta-analysis. The Journal of Clinical Psychiatry, 73, 533-537. doi:10.4088/JCP.11r07356

Bouton, M. E. (1993). Context, time, and memory retrieval in the interference paradigms of Pavlovian learning. Psychological Bulletin, 114, 80-99. doi:10.1037/00332909.114.1.80

Bouton, M. E. (2002). Context, ambiguity, and unlearning: Sources of relapse after behavioural extinction. Biological Psychiatry, 52, 976-986.

Bouton, M. E., \& Todd, T. P. (2014). A fundamental role for context in instrumental learning and extinction. Behavioural Processes, 104, 13-19. doi:10.1016/j.beproc.2014.02.012

Brooks, D. C., Hale, B., Nelson, J. B., \& Bouton, M. E. (1995). Reinstatement after counterconditioning. Animal Learning and Behavior, 23, 383-390. doi:10.3758/BF03198938

Carey, T. A. (2011). Exposure and reorganization: The what and how of effective psychotherapy. Clinical Psychology Review, 31, 236-248. doi:10.1016/j.cpr.2010.04.004

Craske, M. G., \& Barlow, D. H. (2014). Panic disorder and agoraphobia. In D. H. Barlow (Ed.), Clinical handbook of psychological disorders (pp. 1-62). New York, NY: Guilford Press.

Craske, M. G., Hermans, D., \& Vansteenwegen, D. (2006). Fear and learning: From basic 
processes to clinical implications. Washington, D. C.: American Psychological Association.

Craske, M. G., Kircanski, K., Zelikowsky, M., Mystkowski, J., Chowdhury, N., \& Baker, A. (2008). Optimizing inhibitory learning during exposure therapy. Behaviour Research and Therapy, 46,5-27. doi:10.1016/j.brat.2007.10.003

Craske, M. G., Liao, B., Brown, L., \& Vervliet, B. (2012). Role of inhibition in exposure therapy. Journal of Experimental Psychopathology, 3, 322-345. doi:10.5127/jep.026511

Craske, M. G., Treanor, M., Conway, C. C., Zbozinek, T., \& Vervliet, B. (2014). Maximizing exposure therapy: An inhibitory learning approach. Behaviour Research and Therapy, 58, 10-23. doi:10.1016/j.brat.2014.04.006

Culver, N., C. (2013). Extinction-based processes for enhancing the effectiveness of exposure therapy. University of California, Los Angeles.

Culver, N. C., Stoyanova, M. S., \& Craske, M. G. (2011). Clinical relevance of retrieval cues for attenuating context renewal of fear. Journal of Anxiety Disorders, 25, 284-292. doi:10.1016/j.janxdis.2010.10.002

Culver, N. C., Vervliet, B., \& Craske, M. G. (2015). Compound extinction: Using the Rescorla-Wagner model to maximize exposure therapy effects for anxiety disorders. Clinical Psychological Science, 3, 335-348. doi:10.1177/2167702614542103

De Houwer, J., \& Hughes, S. (in press). Evaluative conditioning as a symbol phenomenon : On the relation between evaluative conditioning, evaluative conditioning with instructions, and persuasion. Social Cognition.

Dibbets, P., \& Maes, J. H. R. (2011). The effect of an extinction cue on ABA-renewal: Does 
valence matter? Learning and Motivation, 42, 133-144.

doi:10.1016/j.1mot.2010.12.003

Dibbets, P., Poort, H., \& Arntz, A. (2012). Adding imagery rescripting during extinction leads to less ABA renewal. Journal of Behavior Therapy and Experimental Psychiatry, 43, 614-624. doi:10.1016/j.jbtep.2011.08.006

Dirikx, T., Hermans, D., Vansteenwegen, D., Baeyens, F., \& Eelen, P. (2007). Reinstatement of conditioned responses in human differential fear conditioning. Journal of Behavior Therapy and Experimental Psychiatry, 38, 237-251. doi:10.1016/j.btep.2006.04.001

Dunsmoor, J. E., Ahs, F., Zielinski, D. J., \& LaBar, K. S. (2014). Extinction in multiple virtual reality contexts diminishes fear reinstatement in humans. Neurobiology of Learning and Memory, 113, 157-164. doi:10.1016/j.nlm.2014.02.010

Effting, M, \& Kindt, M. (2007). Contextual control of human fear associations in a renewal paradigm. Behaviour Research and Therapy, 45, 2002-2018. doi:10.1016/j.brat.2007.02.011

Felmingham, K. L., Dobson-Stone, C., Schofield, P. R., Quirk, G. J., \& Bryant, R. A. (2012). The brain-derived neurotrophic factor Val66Met polymorphism predicts response to exposure therapy in posttraumatic stress disorder. Biological Psychiatry, 73, 10591063. doi:10.1016/j.biopsych.2012.10.033

Felmingham, K. L., Kemp, A. H., Williams, L.M., Das, P., Hughes, G., Peduto, A., \& Bryant, R. A. (2007). Anterior cingulate and amygdala changes after cognitive behavioural therapy in posttraumatic stress disorder. Psychological Science, 18, 127-129. doi:10.1111/j.1467-9280.2007.01860.x

Foa, E. B., \& Kozak, M. J. (1986). Emotional processing of fear: Exposure to corrective 
information. Psychological Bulletin, 99, 20-35.

Forsyth, J. P., Eifert, G. H., \& Barrios, V. (2006). Fear conditioning in an emotion regulation context: A fresh perspective on the origins of anxiety disorders. In: M. G. Craske, D. Hermans, \& D. Vansteenwegen (Eds.), From basic processes to clinical implications. Washington, D. C.: American Psychological Association.

Forsyth, J. P., \& Zvolensky, M. J. (2002). Experimental Psychopathology, clinical science and practice: An irrelevant or indispensable alliance? Applied \& Preventive Psychology, $10,243-264$.

Fritzsche, M. (2001). Are cannabinoid receptor knockout mice animal models for schizophrenia? Medical Hypotheses, 56, 638-643. doi:10.1054/mehy.2000.1261

Goldin, P. R., Ziv, M., Jazaieri, H., Werner, K., Kraemer, H., Heimberg, R. G., \& Gross, J. J. (2012). Cognitive reappraisal self-efficacy mediates the effects of individual cognitive-behavioral therapy for social anxiety disorder. Journal of Consulting and Clinical Psychology, 80, 1034-1040. doi:10.1037/a0028555

Goossens, L., Sunaert, S., Peeters, R., Griez, E. J. L., Schruers, K. R. J. (2007). Amygdala hyperfunction in phobic fear normalizes after exposure. Biological Psychiatry, 62, 1119-1125. doi:10.1016/j.biopsych.2007.04.024

Haaker, J., Golkar, A., Hermans, D., \& Lonsdorf, T. B. (2014). A review on human reinstatement studies: An overview and methodological challenges. Learning \& Memory, 21, 424-440. doi:10.1101/lm.036053.114

Haesen, K., \& Vervliet, B. (2015). Beyond extinction: Habituation eliminates conditioned skin conductance across contexts. International Journal of Psychophysiology, 98, 529534. doi:10.1016/j.ijpsycho.2014.11.010 
Hauner, K. K., Mineka, S., Voss, J. L., \& Paller, K. A. (2012). Exposure therapy triggers lasting reorganization of neural fear processing. PNAS: Proceedings of the National Academy of Sciences of the United of America, 109, 9203-9208. doi:10.1073/pnas.1205242109

Hayes, S. C., Strosahl, K. D., \& Wilson, K. G. (2003). Acceptance and commitment therapy: An experiential approach to behavior change. New York, NY: Guilford Press.

Hofmann, S. G. (2008). Cognitive processes during fear acquisition and extinction in animals and humans: Implications for exposure therapy of anxiety disorder. Clinical Psychology Review, 28, 199-210. doi:10.1016/j.cpr.2007.04.009

Hofmann, S. G., Smits, J. A. J., Rosenfield, D., Simon, N., Otto, M. W., Meuret, A. E., ... Pollack, M. H. (2013). D-cycloserine as an augmentation strategy with cognitivebehavioral therapy for social anxiety disorder. The American Journal of Psychiatry, 170, 751-758. doi:10.1176/appi.ajp.2013.12070974

Holmes, E. A., Craske, M. G., \& Graybiel, A. M. (2014). Psychological treatments: A call for mental-health science. Nature, 511, 287-289. doi:10.1038/511287a

Jaycox, L. H., Foa, E. B., \& Moral, A. R. (1998). Influence of emotional engagement and habituation on exposure therapy for PTSD. Journal of Consulting and Clinical Psychology, 66, 185-192. doi:10.1037/0022-006X.66.1.185

Jones, C. R., Vilensky, M. R., Vasey, M. W., \& Fazio, R. H. (2013). Approach behavior can mitigate predominately univalent negative attitudes: Evidence regarding insects and spiders. Emotion, 13, 989-996. doi:10.1037/a0033164

Kerkhof, I., Vansteenwegen, D., Baeyens, F., \& Hermans, D. (2010). Counterconditioning: 
An effective technique for changing conditioned preferences. Experimental Psychology, 58, 31-38. doi:10.1027/1618-3169/a000063

Kimmel, H. D. (1971). Experimental Psychopathology: Recent research and theory. New York: Academic Press.

Kindt, M., \& Soeter, M. (2013). Reconsolidation in a human fear conditioning study: A test of extinction as updating mechanism. Biological Psychology, 92, 43-50. doi:10.1016/j.biopsycho.2011.09.016.

Kircanski, K., Lieberman, M. D., \& Craske, M. G. (2012). Feelings into words: Contributions of language to exposure therapy. Psychological Science, 23, 1086-1091. doi:10.1177/0956797612443830

Krypotos, A.- M., Arnaudova, I., Effting, M., Kindt, M., \& Beckers, T. (2015). Effects of approach-avoidance training on the ectinction and return of fear responses. PLoS ONE, 10, e0131581. doi:10.1371/journal.pone.0131581

Leer, A., \& Engelhard, I. M. (2015). Countering fear renewal: Changes in the UCS representation generalize across contexts. Behavior Therapy, 46, 272-282. doi:10.1016/j.beth.2014.09.012

Lipsitz, J. D., Mannuzza, S., Klein, D. F., Ross, D. C., \& Fyer, A. J. (1999). Specific phobia 10-16 years after treatment. Depression and Anxiety, 10, 105-111.

Lommen, M. J. J., Engelhard, I. M., Sijbrandij, M., van den Hout, M. A., \& Hermans, D. (2013). Pre-trauma individual differences in extinction learning predict posttraumatic stress. Behaviour Research and Therapy, 51, 63-67. doi:10.1016/j.brat.2012.11.004

Lovibond, P. F. (2004). Cognitive processes in extinction. Learning and Memory, 11, 495500. doi:10.1101/lm.79604 
Luyten, L., Vansteenwegen, D., van Kuyck, K., Gabriels, L., \& Nuttin, B. (2011). Contextual conditioning in rats as an animal model for generalized anxiety disorder. Cognitive, Affective, and Behavioral Neuroscience, 11, 228-244. doi:10.3758/s13415-011-0021-6

Mineka, S., \& Zinbarg, R. (2006). A contemporary learning theory perspective on the etiology of anxiety disorder. American Psychologist, 61, 10-26. doi:10.1037/003-066X.61.1.10

McConnell, B. L., \& Miller, R. R. (2014). Associative accounts of recovery-from-extinction effects. Learning and Motivation, 46, 1-15. doi:10.1016/j.1mot.2014.01.003

McHugh, R. K., \& Barlow, D. H. (2010). The dissemination and implementation of evidencebased psychological treatments: A review of current efforts. American Psychologist, 65, 73-84. doi:10.1037/a0018121

McNally, R. J. (2007). Mechanisms of exposure therapy: How neuroscience can improve psychological treatments for anxiety disorders. Clinical Psychology Review, 27, 750759. doi:10.1016/j.cpr.2007.01.003

Milad, M. R., Wright, C. I., Orr, S. P., Pitman, R. K., Quirk, G. J., \& Rauch, S. L. (2007). Recall of fear extinction in humans activates the ventromedial prefrontal cortex and hippocampus in concert. Biological Psychiatry, 62, 446-454. doi:10.1016/j.biopsych.2006.10.011

Milad, M. R., Quinn, B. T., Pitman, R. K., Orr. S. P., Fischl, B., \& Rauch, S. L. (2005). Thickness of ventromedial prefrontal cortex in humans is correlated with extinction memory. PNAS: Proceedings of the National Academy of Sciences of the United of America, 102, 10706-10711. doi:10.1073/pnas.0502441102

Milad, M. R., \& Quirk, G. J. (2012). Fear extinction as a model for translational neuroscience: 
Ten years of progress. Annual Review of Psychology, 63, 129-151.

doi:10.1146/annurev.psych.121208.131631

Mystkowski, J. L., Craske, M. G., Echiverri, A. M., \& Labus, J. S. (2006). Mental reinstatement of context and return of fear in spider-fearful participants. Behavior Therapy, 37, 49-60. doi:10.1016/j.beth.2005.04.001

Niles, A. N., Craske, M. G., Lieberman, M. D., \& Hur, C. (2015). Affect labeling enhances exposure effectiveness for public speaking anxiety. Behaviour Research and Therapy, 68, 27-36. doi:10.1016/j.brat.2015.03.004

Norberg, M. M., Krystal, J. H., \& Tolin, D. F. (2008). A meta-analysis of d-cycloserine and the facilitation of fear extinction and exposure therapy. Biological Psychiatry, 63, 1118-1126. doi:10.1016/j.biopsych.2008.01.012

Ori, R., Amos, T., Bergman, H., Soares-Weiser, K., Ipser, J. C., \& Stein, D. J. (2015). Augmentation of cognitive and behavioural therapies (CBT) with d-cycloserine for anxiety and related disorders. Cochrane Database of Systematic Reviews, 2015(5), 1131. doi:10.1002/14651858.CD007803.pub2

Pavlov, I. P. (1927). Conditioned reflexes: An investigation of the physiological activity of the cerebral cortex. London, England: Oxford University Press.

Phelps, E. A., Delgado, M. R., Nearing, K. J., \& LeDoux, J. E. (2004). Extinction learning in humans: Role of the amygdala and vmPFC. Neuron, 43, 897-905.

Pittig, A., van den Berg, L., \& Vervliet, B. (2016). The key role of extinction learning in anxiety disorders: Behavioral strategies to enhance exposure-based treatments. Current Opinion in Psychiatry, 29, 39-47. doi:10.1097/YCO.0000000000000220

Rescorla, R. A. (1973). Effects of US habituation following conditioning. Journal of 
Comparative and Physiological Psychology, 82, 137-143.

Rodrigues, H., Figueira, I., Lopes, A., Gonçalves, R., Mendlowicz, M. V., Coutinho, E. S. F., \& Ventura, P. (2014). Does d-cycloserine enhance exposure therapy for anxiety disorder in humans ? A meta-analysis. PLoS ONE, 9, e93519. doi:10.1371/journal.pone.0093519

Rowe, M. K., \& Craske, M. G. (1998a). Effects of varied-stimulus exposure training on fear reduction and return of fear. Behaviour Research and Therapy, 36, 719-734. doi:10.1016/S0005-7967(97)100017-1

Rowe, M. K., \& Craske, M. G. (1998 b). Effects of an expanding-spaced vs massed exposure schedule on fear reduction and return of fear. Behaviour Research and Therapy, 36, 701-717. doi:10.1016/S0005-7967(97)10016-X

Simpson, H. B., Liebowitz, M. R., Foa, E. B., Kozak, M. J., Schmidt, A. B., Rowan, V., ... Campeas, R. (2004). Post-treatment effects of exposure therapy and clomipramine in obsessive-compulsive disorder. Depression and Anxiety, 19, 225-233. doi:10.1002/da.20003

Sloan, D. M. (2014). Introduction: Using experimental psychopathology to advance behavior therapy. Behavior Therapy, 45, 589-593. doi:10.1016/j.beth.2014.03.007

Soliman, F., Glatt, C. E., Bath, K. G., Levita, L., Jones, R. M., Pattwell, S. S., ... Casey, B. J. (2010). A genetic variant BDNF polymorphism alters extinction learning in both mouse and human. Science, 327, 863-866. doi:10.1126/science.1181886

Steinert, C., Hofmann, M., Kruse, J., \& Leichsenring, F. (2014). Relapse rates after psychotherapy for depression - stable long-term effects? A meta-analysis. Journal of Affective Disorders, 168, 107-118. doi:10.1016/j.jad.2014.06.043 
Tryon, W. (2005). Possible mechanisms for why desensitization and exposure therapy work. Clinical Psychology Review, 25, 67-95. doi:10.1016/j.cpr.2004.08.005

Tsao, J. C. I., Craske, M. G. (2000). Timing of treatment and return of fear: Effects of massed, uniform, and expanded spaced exposure schedules. Behavior Therapy, 31, 479-497. doi:10.1016/S0005-7894(00)80026-X

Van den Hout, M. (1999). Armies of idiots and idiosyncrasies: On reductions in experimental psychopathology. Behaviour Research and Therapy, 37, 135-145.

Van den Hout, M. A., Engelhard, I. M., \& McNally, R. J. (in press). Thoughts on experimental psychopathology. Psychopathology Review. doi:10.5127/pr.045115

Van Meurs, B., Wiggert, N., Wicker, I., \& Lissek, S. (2014). Maladaptive behavioral consequences of conditioned fear generalization: A pronounced, yet sparsely studied feature of anxiety pathology. Behavior Research and Therapy, 57, 29-37. doi:10.1016/j.brat.2014.03.009

Van Uijen, S. L., van den Hout, M., \& Engelhard, I. (2015). Active approach does not add to the effects of in vivo exposure. Journal of Experimental Psychopathology, 6, 112-125. doi:10.5127/jep.042014

Vansteenwegen, D., Vervliet, B., Hermans, D., Beckers, T., Baeyens, F., \& Eelen, P. (2006). Stronger renewal in human fear conditioning when tested with an acquisition retrieval cue than with an extinction retrieval cue. Behaviour Research and Therapy, 44, 17171725. doi:10.1016/j.brat.2005.10.014

Vansteenwegen, D., Vervliet, B., Iberico, C., Baeyens, F., van den Bergh, O., \& Hermans, D. 
(2007). The repeated confrontation with videotapes of spiders in multiple contexts attenuates renewal of fear in spider-anxious students. Behaviour Research and Therapy, 45, 1169-1179. doi:10.1016/j.brat.2006.08.023

Vervliet, B. (2008). Learning and memory in conditioned fear extinction: Effects of dcycloserine. Acta Psychologica, 127, 601-613. doi:10.1016/j.actpsy.2007.07.001

Vervliet, B., Baeyens, F., Van den Bergh, O., \& Hermans, D. (2013). Extinction, generalization, and return of fear: A critical review of renewal research in humans. Biological Psychology, 92, 51-59. doi:10.1016/j.biopsycho.2012.01.006

Vervliet, B., Craske, M. G., \& Hermans, D. (2013). Fear extinction and relapse: State of the art. Annual Review of Clinical Psychology, 9, 215-248. doi:10.1146/annurev-clinpsy$050212-185542$

Vervliet, B., \& Indekeu, E. (2015). Low-cost avoidance behaviors are resistant to fear extinction in humans. Frontiers in Behavioral Neuroscience, 9, 351. doi:10.3389/fnbeh.2015.00351

Vervliet, B., Kindt, M., Vansteenwegen, D., \& Hermans, D. (2010). Fear generalization in humans: Impact of verbal instructions. Behaviour Research and Therapy, 48, 38-43. doi:10.1016/j.brat.2009.09.005

Vervliet, B., \& Raes, F. (2013). Criteria of validity in experimental psychopathology: Application to models of anxiety and depression. Psychological Medicine, 43, 22412244. doi:10.1017/S0033291712002267

Vervliet, B., Vansteenwegen, D., Baeyens, F., Hermans, D., \& Eelen, P. (2005). Return of 
fear in a human differential conditioning paradigm caused by stimulus change after extinction. Behaviour Research and Therapy, 43, 357-371.

doi:10.1016/j.brat.2004.02.005

Walker, D. L., \& Davis, M. (2002). The role of amygdale glutamate receptors in fear learning, fear-potentiated startle, and extinction. Pharmacology, Biochemistry and Behavior, 71, 379-392.

Waters, A., LeBeau, R., \& Craske, M. (in press). Experimental psychopathology: An integrative model. Psychopathology Review.

Zlomuzica, A., Preusser, F., Schneider, S., \& Margraf, J. (2015). Increased perceived selfefficacy facilitates the extinction of fear in healthy participants. Frontiers in Behavioral Neuroscience, 9, 1-12. doi:10.3389/fnbeh.2015.00270

Zvolensky, M. J., Forsyth, J. P., \& Johnson, K. (2013). Laboratory methods in experimental psychopathology. In J. S. Comer \& P. C. Kendall (Eds.), The Oxford handbook of research strategies for clinical psychology (pp. 7-23). New York, NY: Oxford University Press. 